\title{
Catatonia following biparietal infarction with spontaneous
} recovery

\author{
Robert J.M.W. Howard and T.S. Low-Beer
}

Department of Medicine, Selly Oak Hospital, Raddlebarn Road, Selly Oak, Birmingham B29 6JD, UK.

Summary: We describe a case of catatonic stupor following simultaneous biparietal infarction. The patient recovered, a result not previously described in catatonia caused by this pattern of cerebral infarct.

\section{Introduction}

Catatonia is well recognized in association with organic brain conditions as well as with schizophrenia and the affective disorders. We report a patient displaying all the features of catatonia, namely waxy flexibility, bizarre posturing, stupor, mutism, and negativism, following spontaneous biparietal infarction. A previous report ${ }^{1}$ has described a patient who, following biparietal infarction, developed incomplete features of catatonia which did not recover. Our patient made a spontaneous recovery from his catatonic state, suggesting that the prognosis for this condition following biparietal infarction may be better than reported.

\section{Case report}

A man aged 72 years returned home from a short visit to the launderette in a state of confusion and agitation. Perplexed, abusive, and shouting for his wife, who was present, he was admitted to a psychiatric hospital. There he refused to answer any questions, but his wife and general practitioner indicated that he had no past medical or psychiatric history, was on no medication, and had sustained no head injury. He was noted to be in uncontrolled atrial fibrillation, and the blood pressure was $160 / 100 \mathrm{mmHg}$. While he resisted systematic neurological examination, no abnormality of limbs, eyes, or cranial nerves was apparent.

He refused all food and drink, and a week later had developed a right middle lobe pneumonia. Transferred to a general hospital, he gave a superficial impression of unconsciousness, but resisted purposefully any attempt to feed or examine him. A computed tomographic brain scan (Figure 1) showed areas of recent

Correspondence: R.J.M.W. Howard, M.A., M.B., The Bethlem Royal Hospital, Monks Orchard Road, Beckenham, Kent BR3 3BX, UK.

Accepted: 30 November 1988

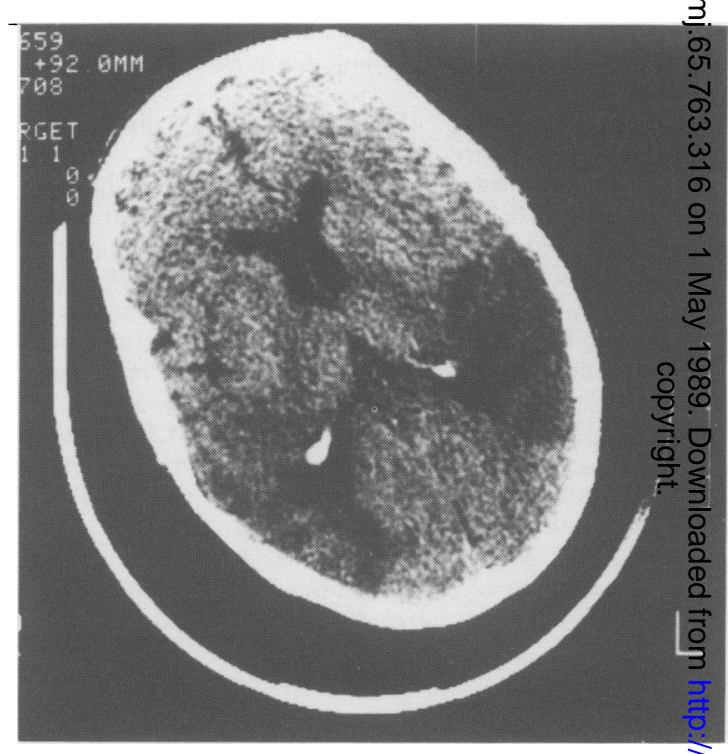

Figure 1 Computed tomography of head showi bilateral parietal occipital infarction.

infarction in both posterior parieto-occipital regioß̂̊s, principally in the watershed areas between the midd̆ and posterior cerebral artery supply areas. Electioencephalography gave only modest non-specific abnormalities, while visual evoked responses showed intact visual pathways.

The pneumonia responded to intravenous antibiotics within 5 days, and he returned to sinus rhyth but remained mute apart from incomprehensibse muttering. He continued to resist feeding, and pul[Ed out his intravenous and nasogastric tubes. He refused to open his eyes or mouth when asked, and attemptsळुo move his arms or legs, or open his eyes and mouth, were forcibly resisted. Waxy flexibility of his arms ws present. He adopted strange postures, sitting upright

(C) The Fellowship of Postgraduate Medicine, $1 \frac{\stackrel{9}{8} 9}{8}$ 
in bed holding his arms up like flexed birds' wings. Over the following 6 weeks he slowly improved to the point where he would speak rationally to his wife, but his behaviour was disinhibited. He would grab at the nurses, refuse to comply with instructions, and showed wide swings of mood and emotion. At the end of 3 months he was eating and drinking normally, and no longer showed signs of catatonia. His personality remained infantile, and neuropsychological assessment revealed amnesic confusion combined with both expressive and receptive forms of dysphasia. He returned home to be nursed by his wife.

\section{Discussion}

Catatonia has both organic and psychiatric causes. In a series of 25 cases of catatonia, ${ }^{2} 36 \%$ were found to have schizophrenic or affective illness, $20 \%$ had a probable organic cause, and in $40 \%$ no organic or psychiatric cause was found. Cerebrovascular disease is a well described precipitant: subarachnoid haemorr-

\section{References}

1. Tippin, J. \& Dunner, F.J. Bi-parietal infarctions in a patient with catatonia. Am J Psychiatry 1981, 138: $1386-1387$.

2. Barnes, M.P., Saunders, M., Walls, T.J., Saunders, I. \& Kirk, C.A. The syndrome of Karl Ludwig Kahlbaum. $J$ Neurol Neurosurg Psychiatry 1986, 49: 991-996.

3. Thompson, G.N. Cerebral lesions simulating catatonia; three case reports. Biol Psychiatry 1970, 2: 59-64. hage, ${ }^{3}$ cortical venous thrombosis, ${ }^{4}$ thrombotic thrombocytopenia purpura, ${ }^{5}$ subdural haematoma, ${ }^{6}$ and cerebral infarction ${ }^{1}$ have been implicated.

Tippin and Dunner described a 45 year old man with catatonia following biparietal infarction. He was withdrawn and mute and maintained a bizarre posture, sitting rigidly in a chair leaning towards the right. This patient showed no 'waxy flexibility'; that is to say it was not possible to place his limbs and body in positions which he would then maintain. The catatonia did not improve despite treatment with electroconvulsive therapy and haloperidol. Most of the patients described by Barnes et al. ${ }^{2}$ either recovered spontaneously or following electroconvulsive therapy. They found those with an acute and rapidly progressive course, 'acute lethal catatonia', to have the worst prognosis, 3 out of 4 dying of acute renal failure. Persistence of the catatonic state as described by Tippin and Dunner may, however, be atypical. The recovery demonstrated by our patient is more in accord with the result of Barnes' series, and suggests that the prognosis for recovery from catatonia following biparietal infarction may be good.

4. Gangadhar, B.N., Keshavan, M.S., Goswani, U. \& Vasuder Rao, T. Cortical venous thrombosis presenting as catatonia. A clinicopathological report. $J$ Clin Psychiatry 1983, 44: 109-110.

5. Read, S.L. Catatonia in thrombotic thrombocytopenic purpura. J Clin Psychol 1984, 44: 343-344.

6. Woods, S.W. Catatonia in a patient with sub-dural haematomas. Am J Psychiatry 1980, 137: 983-984. 